\title{
Morphometric, functional and sexual maturity of the deep-sea red crab Chaceon affinis inhabiting Canary Island waters: chronology of maturation
}

\author{
V. Fernández-Vergaz, L. J. López Abellán*, E. Balguerías \\ Centro Oceanográfico de Canarias, Instituto Español de Oceanografía, Carretera de San Andrés s/n, \\ 38120 Santa Cruz de Tenerife, Spain
}

\begin{abstract}
Although Chaceon affinis is practically unknown to Canarian fishermen, relatively abundant quantities of deep-sea red crab C. affinis have been found in all trap surveys conducted around the Canary Islands in the last $10 \mathrm{yr}$, in which waters deeper than $550 \mathrm{~m}$ have been examined. From July 1994 to May 1996, monthly samples were taken from north-eastern waters off Tenerife using a variety of trap designs. Crabs were caught at depths ranging from 550 to $1200 \mathrm{~m}$ on muddyrocky bottoms. A variety of measurements were taken from each specimen, and most of these showed linear and isometric growth relative to carapace width (CW). Male chela width (ChW) and female abdomen width (AW) did not show such evident allometry as other crab species. Changes in growth of these features, considered as secondary sexual characters, were used to discriminate morphometrically immature crabs from mature crabs, using hierarchical cluster analysis. Different morphometric groups were distinguished, for both males and females, and male ChW and female AW were plotted against CW. Regressions were calculated separately for each cluster to test the discrimination statistically. Morphometric size at maturity was initially estimated and compared with data on gonad stage. This comparison revealed a high correlation in males between morphometric and sexual maturity, which is reached at about $129 \mathrm{~mm} \mathrm{CW}$. However, most females become morphometrically mature before their ovaries mature and before copulation (at sizes of $\sim 99,108$ and $113 \mathrm{~mm} \mathrm{CW}$, respectively).
\end{abstract}

KEY WORDS: Biology $\cdot$ Maturity $\cdot$ Chaceon affinis $\cdot$ Geryonidae $\cdot$ Canary Islands

\section{INTRODUCTION}

Several species of the red crab Chaceon affinis (Geryonidae Colosi, 1923) are exploited commercially in various parts of the world. Of the 15 species of the genus Chaceon Manning \& Holthuis, 1989, 3 are widespread throughout the Atlantic Ocean and support relatively important fisheries: C. quinquedens in Canada and the USA (Lux et al. 1982, Elner et al. 1987), C. fenneri in the Gulf of Mexico (Manning \& Holthuis 1984, Erdman \& Blake 1988), and C. maritae along the west coast of Africa (Días \& Seita Machado 1973, Intes \&

*Corresponding author. E-mail: luis.lopez@ieo.rcanaria.es
Le Loeuff 1976, Cayre \& Bouchereau 1977, Beyers \& Wilke 1980, Melville-Smith 1988, López Abellán \& García Talavera 1992).

Chaceon affinis is the largest epibenthic brachyuran of the Geryonidae family (Manning \& Holthuis 1989), inhabiting oceanic seamounts throughout the eastern Atlantic Ocean, from Iceland to Senegal, and found around all the Macaronesian Islands (Milne Edwards \& Bouvier 1894, Kjenerud 1967, Samuelsen 1975, Manning \& Holthuis 1981, Sánchez \& Olaso 1985, Santana et al. 1985, Lozano et al. 1992, López Abellán et al. 1994). Although there are some local fisheries based on this species, such as that located in north-western Spain (Galicia Bank) (Pérez Gándaras in Sánchez \& Olaso 1985), this species was first caught in the Canary 
Islands in July 1985 during a scientific survey (Lozano et al. 1992), and has since been readily fished in all trap surveys conducted around the Canaries at depths greater than $550 \mathrm{~m}$.

A distinction must be made between functional and sexual maturity. According to Hartnoll (1974), a crab is considered mature at the intermoult period, during which it can successfully mate. It is generally accepted that brachyuran maturity cannot be determined by simple observation of gonad condition, because development and ovulation often occur some time after mating (Haefner 1977). Hartnoll (1974) showed that in some species there are ontogenetic variations in the pattern of relative growth of some body parts (male chelae and female abdomen), indicating that there are differences in growth not only between sexes, but also between immature and mature individuals. Some sexual dimorphism and morphometric changes are evidently beneficial to reproductive behaviour and a requirement for successful reproduction. Males combat (chela), court, copulate and protect females for some time after copulation, while females carry and protect the eggs (abdomen) during the incubatory period.

During postlarval development, crustaceans have 2 different growth phases: the puberal phase and the mature phase. Crustaceans reach morphometric maturity at the puberty moult, which is characterized by changes in the relative growth of some appendages, visible as breaks in the relative growth line, and changing the slope and/or the elevation of the line. This phenomenon has been studied by several authors in a number of brachyuran species by a variety of methods. Some investigators discriminated between juveniles and adults, determining the discontinuity in the scatter of points by the naked eye, as did Brown \& Powell (1972) for male Chionoecetes bairdi, Haley (1973) for female Ocypode ceratophthalmus, Davidson \& Marsden (1987) for male Ovalipes catharus, and Haefner (1990) for Callinectes ornatus. Others used an iterative program developed and described by Somerton (1980) for Paralithodes camtschatica and male Chionoecetes bairdi, as did Gaertner \& Laloé (1986) for Geryon maritae. The most recent studies make use of principal components and discrimination analysis; e.g., those of Conan \& Comeau (1986), Sainte-Marie \& Hazel (1992) and Sainte-Marie et al. (1995) with male Chionoecetes opilio.

However, morphometric maturity means that the crab is morphometrically functional for reproduction, independent of whether it becomes physiologically mature before or after reaching morphometric maturity. Therefore, a crab should be classified as adult only when it reaches both morphometric and physiological maturity. Size at maturity for Chaceon affinis in the Canary Islands has been determined mainly using morphometric crite- ria, and these results have been compared with gonad observations and vulvae condition to identify the sequence of maturation up to reproductive capability.

\section{MATERIALS AND METHODS}

Between July 1994 and May 1996, monthly samples of Chaceon affinis were taken from Tenerife waters (Fig. 1), using a variety of designs of traps, on rockymuddy bottoms and at depths ranging from 550 to $1200 \mathrm{~m}$. Operations were conducted from north-eastern Tenerife, on board a fishing boat operated by the Instituto Español de Oceanografía. The traps were baited with sardine or mackerel, and times between setting and hauling in ranged from 24 to $48 \mathrm{~h}$.

A total of 631 crabs were collected, 362 males and 269 females. At the laboratory, several measurements were recorded for each specimen using a digital calliper with $0.01 \mathrm{~mm}$ precision: carapace width $(\mathrm{CW}$, the distance between the 5th lateral spine tips), carapace length $(\mathrm{CL}$, midline distance from the diastema between the rostral teeth to the posterior carapace edge), left and right chela width (LChW and RChW,

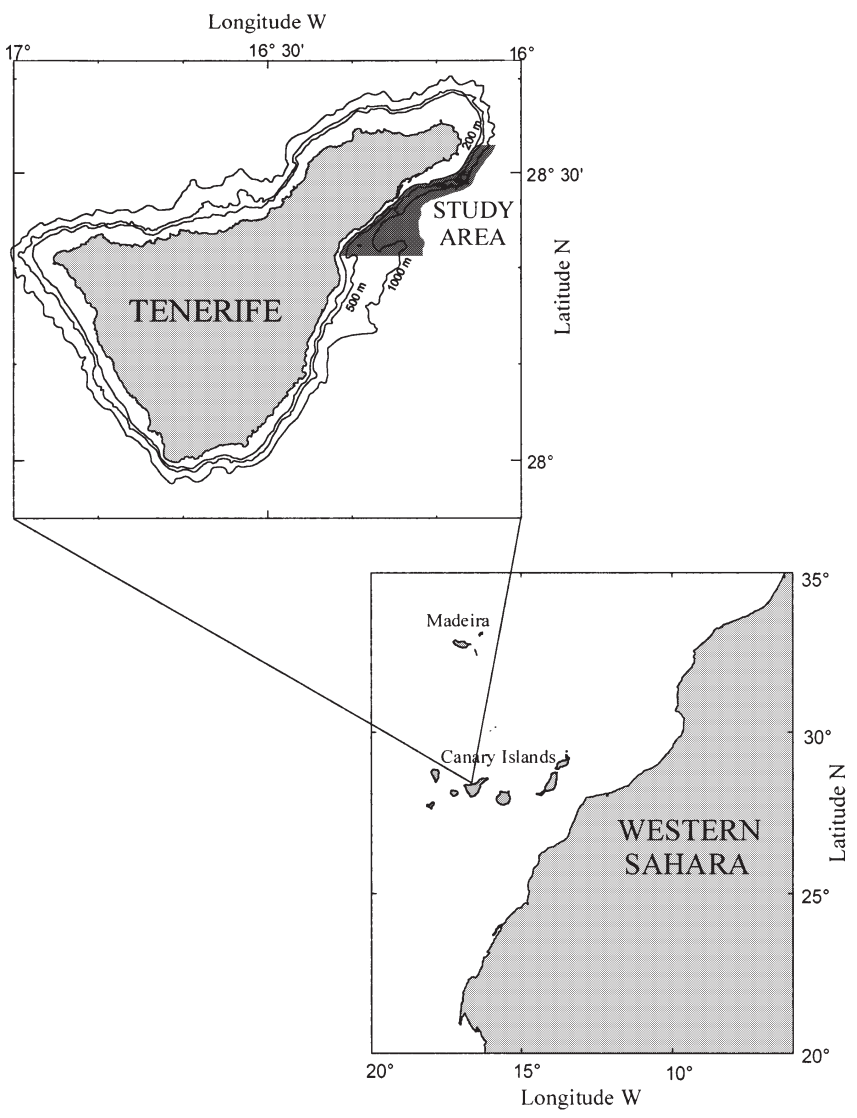

Fig. 1. Location of study area. Shaded area to northeast of Tenerife showing depths surveyed; dots: deployment position 
maximum width at dactylus base), left and right chela length (LChL and $\mathrm{RChL}$, distance from more distal point on the palm base to the dactylus tip), and female maximum abdomen width (AW). The total length of each walking leg (pereiopods) (RPL1, LPL1, ..., RPL5, LPL5, distance from the ischium base to the dactylus tip) was also recorded. The total wet weight was recorded with $0.1 \mathrm{~g}$ precision, as was the gonad weight.

In the morphometric analysis, different methods were used to find indications corroborating the hypothesis of an allometric growth - maturation relationship. Thus, linear least-squares regression equations were fitted for each variable, with $\mathrm{CW}$ as the independent variable. Furthermore, the constant of allometry was estimated for all relationships based on log-log transformations of body measurements. Hierarchical cluster analyses were made for all variables, using the squared euclidean distance coefficient and the UPGMA linkage method. The same method was used in the cluster analyses for cases, but only the more significant variables selected after the variable cluster analyses were taken into consideration. Principal component analyses (PCA) were also made for all morphometric variables, for both males and females. Both analyses were conducted with the SPSS statistical program (Norusis 1994).

After classifying each individual as morphometrically immature or mature, bivariate scatter plots were made of those body parts which bear secondary sexual characteristics (male RChW and female AW) against CW. For each sex, a linear least-squares regression equation was fitted for the total sample as well as for each group separately. A statistical test for coincidental regressions described by Zar (1974) and used by Somerton (1980) was applied to determine if the scatter of points fit the resulting linear regression lines better than a single line.

The same analysis was carried out for the allometric relationships of the resulting groups. However, although the points fit better to more than 1 line following the first test, a covariance analysis (Zar 1974) was still needed to determine whether the differences between regressions were due to significant differences within slopes or elevations. That is to say, if the moult to maturity is accompanied by a change in relative growth rate or by a pronounced increase in size of the secondary sexual characters.

The next step was to validate the results of morphometric analyses comparing gonad condition, abdomen width and vulvae stage. The gonadosomatic index (GI) was calculated with the following expression:

$$
\text { GI }=\frac{\text { gonad weight }}{\text { total weight }} \times 100
$$

Female ovarian development was noted based on colour criteria following the maturation scales described by Haefner (1977) for Chaceon (Geryon) quinquedens and by Erdman \& Blake (1988) for Chaceon (Geryon) fenneri. The ovarian development stages were classified as immature: very small and colourless, or absent; early: small, ivory to light orange in colour; intermediate: orange, lilac or light violet, and of medium size; advanced: violet, grey or brown, well developed; mature: purple and brownish purple, occupying a large space in the visceral cavity.

The female abdomen width was also examined to assess maturity. An abdomen narrower than the sternum is considered immature because it has not yet reached a large enough size to form the incubatory chamber in which the eggs are protected during hatching. A mature abdomen is wider than the sternum. An abdomen of equal width to the sternum represents the intermediate phase in abdomen maturation. We also considered 3 different stages of vulvae. Crabs with closed vulvae are virgin, crabs with partially open vulvae are also virgin but in a more developed stage of maturity, and finally vulvae as fully open holes are evidence that the crab has, at some time, copulated.

Cross tabulations (contingency tables) of abdomen morphology, vulvae stage and ovarian development were tested by chi-square analysis. These data were compared with the bivariate discontinuities to assess the reliability of the bivariate analysis in predicting stages of sexual maturity.

Finally, for each procedure used in maturity determination, the proportion of individuals classified as adults in each size interval was fit to a logistic curve and size at maturity was estimated in each case, using the following equation.

$$
p=\frac{100}{1+\mathrm{e}^{-(a+b \times C W)}}
$$

where $p$ is the proportion of mature individuals, $C W$ is the midpoint of a size class interval, and $a$ and $b$ are undetermined parameters.

\section{RESULTS AND DISCUSSION}

\section{Size-frequency distribution}

Male Chaceon affinis ranged from 65 to $189 \mathrm{~mm} \mathrm{CW}$ $($ mean $=130 \mathrm{~mm})$ and from 46 to $1757 \mathrm{~g}($ mean $=609 \mathrm{~g})$. Females, smaller and lighter than males, ranged from 61 to $165 \mathrm{~mm} \mathrm{CW}$ (mean $=120 \mathrm{~mm}$ ) and from 47 to $1095 \mathrm{~g}($ mean $=422 \mathrm{~g})$. Striking differences in size between sexes were found, with males reaching substantially greater sizes than females (Fig. 2). Male sizefrequency distribution tends to be bimodal, whereas females show a main modal component at sizes between the 2 main male modes. 


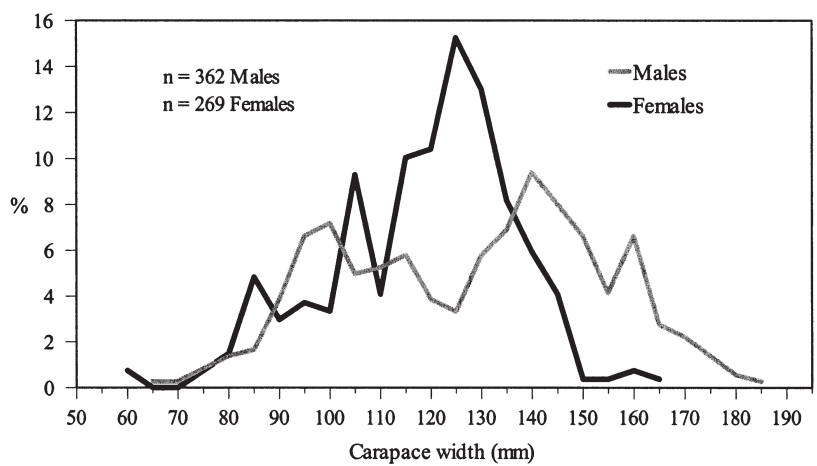

Fig. 2. Chaceon affinis. Length-frequency distribution by sex for all individuals analysed

\section{Regression analysis}

The relationship between CW and CL is linear and isometric for both males and females (Fig. 3). Taking all regressions between CW as an independent variable, and cheliped or walking leg measurements as variables, the slope is greater for males than for females. Hence, for leg size there is clear sexual dimorphism; whereas in females leg growth relative to CW is
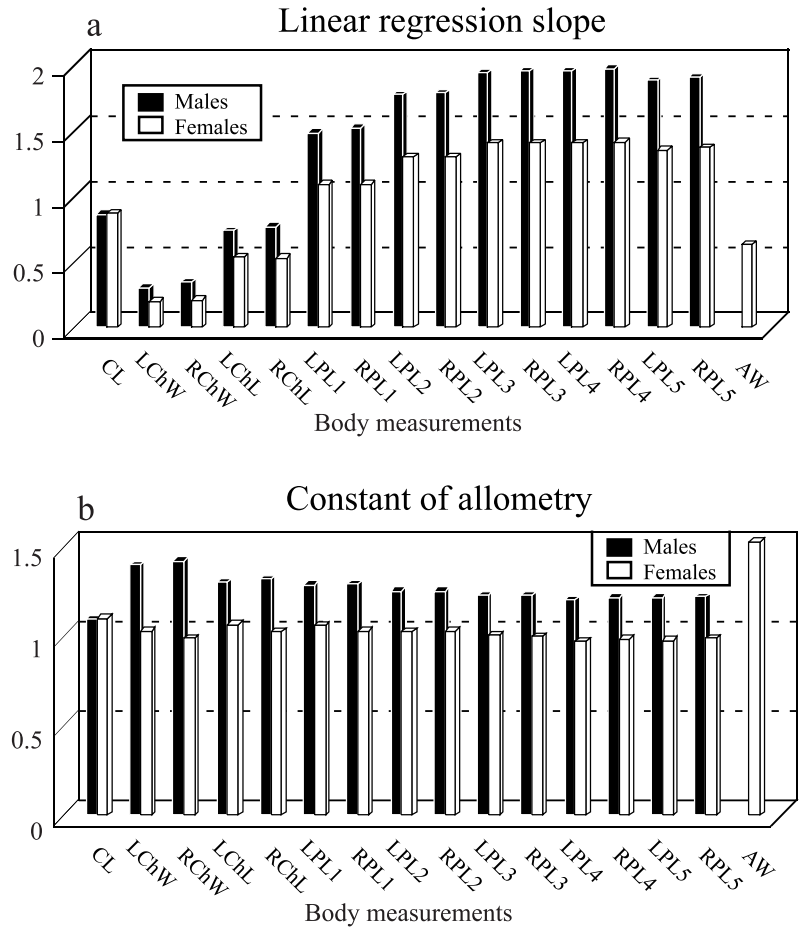

Fig. 3. Chaceon affinis. (a) Linear regression slopes and (b) allometry constant by sex obtained from relationships between carapace width (CW) and carapace length (CL), left and right chela width (LChW, RChW), left and right chela length (LChL, RChL), total length of each walking leg (RPL1, LPL1, .., RPL5, LPL5), and female maximum abdomen width (AW) isometric or shows slightly negative allometry, males display positive allometry in all relationships. The level of allometry is maximum for both male ChW and for female AW.

The analysis revealed sexual dimorphism of the chelae, used by the male in combat, display and courtship, which is related to eventual success. According to Mori \& Relini (1982) and Elner et al. (1987), the chelae are used to express aggressive activity towards other specimens and to feed.

The sexual dimorphism of the other walking legs could also be related to behavioural patterns during the pre-mating embrace. Furthermore, visual examination of individuals revealed a striking sexual dimorphism of the abdomen that is related to the different function of the male and female pleopods. In the latter, the developing eggs are attached to the pleopods throughout incubation, with the abdomen forming a cover to facilitate fixation and to act as an incubatory chamber. As Hartnoll (1974) explained, the female abdomen must reach a greater size than in the male to accomplish this function efficiently.

The regression analyses reveal intra-sexual variations in growth rate, generating differential growth throughout an individual lifespan, and resulting in greater allometry for male chelae and for female abdomen width (Fig. 3), as described for other brachyuran species.

\section{Secondary sexual characters and size at maturity}

The hierarchical classification analysis for the male variables indicates a clear dissimilarity between $\mathrm{RChW}$ and the other variables, the shortest distance being with LChW (Fig. 4). Female results reveal a clear distance between one variable (AW) and the others, which is closely related to $\mathrm{ChW}$. Male and female data show differentiated groups relevant to the role they play. Thus, Pereiopod Pairs 2 to 5 mainly reflect movement capability (walking legs); carapace dimensions standard growth together with length of the chelae and the first pair of pereiopods; chelae width different behavioural activities such as feeding, fighting or reproduction; and abdomen dimensions reproduction.

The PCA for all male variables detected the presence of a principal factor explaining a percentage of variability as high as 98.2, strongly related to all the body measurements, and a second factor that explains only $0.5 \%$ of variability and that is clearly related to the $\mathrm{RChW}$ variable. As a result of this analysis we can deduce that Factor 1 expresses size and Factor 2 morphometric maturity. In contrast, analysis of the female data revealed the existence of a principal factor explaining a total of $96.1 \%$ variability and expressing 

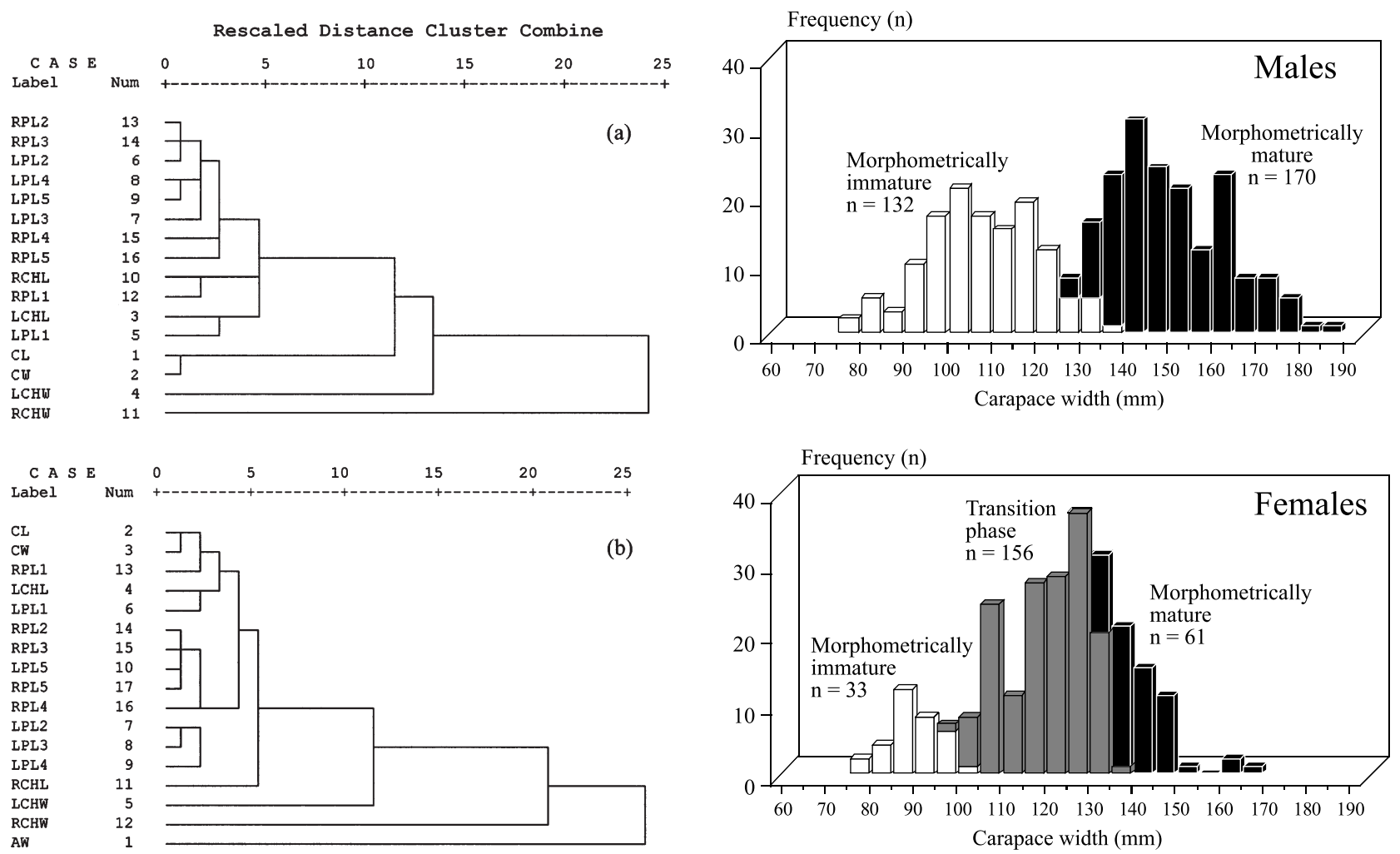

Fig. 4. Chaceon affinis. Dendrogram using hierarchical classification analysis of variables. (a) Males, (b) females. Abbreviations as in Fig. 3

Fig. 5. Chaceon affinis. Length-frequency distribution after clustering cases: analysis as a function of morphometric maturity for (a) males and (b) females

size, and 2 other factors related to LChW and RChW respectively.

Previous analyses indicate that male $\mathrm{RChW}$ and female AW should be viewed as secondary sexual characters, considering the higher level of allometry of both variables and their hypothetical relationship to reproductive functions. No differences in this respect were found between the present study and similar studies on crabs and, in particular, to those on the Chaceon spp. (Gaertner \& Laloé 1986).

The hierarchical cluster analyses for cases (except for walking-leg length variables, which provide no further information) was based on only carapace, cheliped and chelae measurements, but included the abdomen width for females. It revealed 2 different groups for both males and females, and in females one of these groups consists of 2 subgroups. The cluster analyses reveal differences in the morphometric relationships between individuals, allowing the establishing of hypothetical borders between functional maturation phases.

The size-frequency histograms after clustering cases indicate that both sexes are morphometrically segregated by size (Fig. 5). The male histogram can be split into 2 groups: one including those individuals consid-

ered 'morphometrically immature', or 'juvenile', and the other those considered as 'morphometrically mature' or 'adult'. The 2 main assemblages overlap between the 125 and $135 \mathrm{~mm} \mathrm{CW}$ size classes. It is therefore within this size interval that, theoretically, males reach morphometric maturity when the puberty moult occurs. However, in the female assemblages we also observed an intermediate group corresponding to an unknown mixture of juveniles and adults or to another growth phase.

Male RChW and female AW were plotted against CW (Fig. 6). The plot between RChW and CW of males fits significantly better $(p<0.025)$ when 2 different regression lines are plotted. Likewise, female (AW-CW relationship) points also fit better when $>1$ line is plotted ( $p<0.01$ ), if the 3 groups observed are considered. However, the statistical test shows that both groups of points to the left fit better to 2 different regression lines than to a single line $(p<0.0025)$, whereas the intermediate points and those on the extreme right fit better to a single regression line, taking the 2 last groups as 1 morphometrical group. Therefore, 2 groups were considered for both sexes: one of morphometrically immature individuals (MII) and the other of morphometrically mature individuals (MMI). 

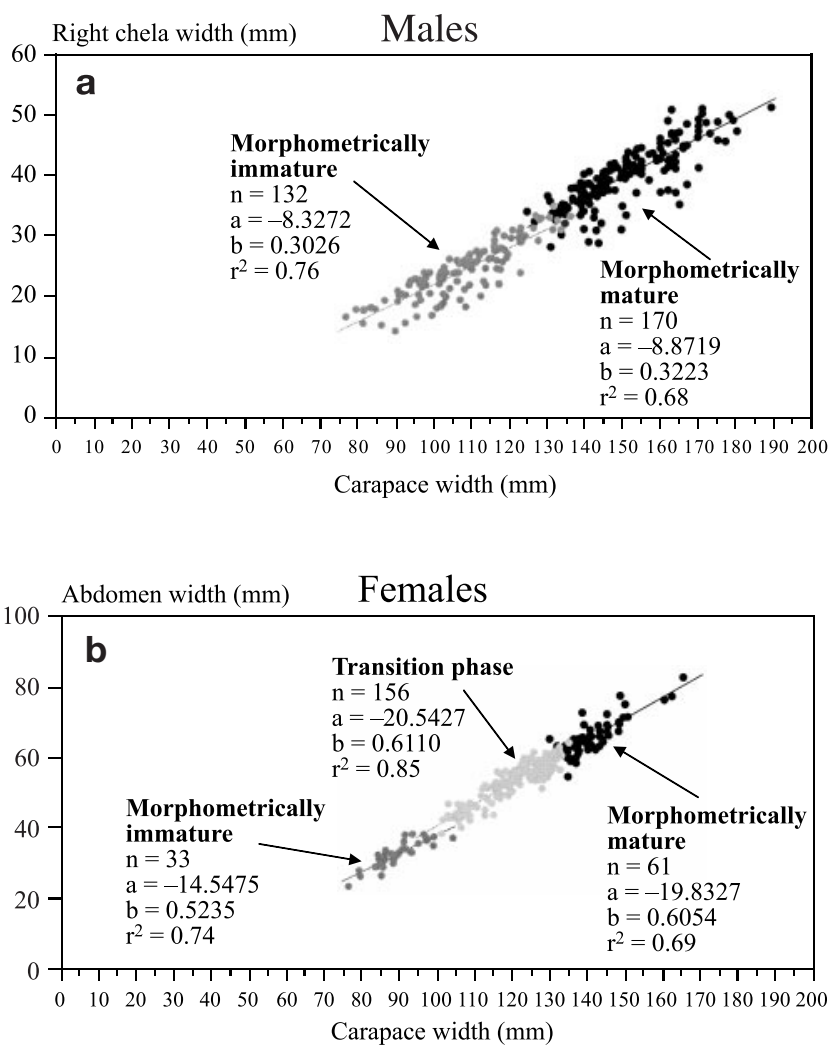

Fig. 6. Chaceon affinis. Bivariate scatter plots of secondary sexual characters and lines fitted to each group of points representing morphometric maturity stages of (a) males and (b) females

The allometric relationship differences between MII and MMI are statistically significant in both cases (males, $\mathrm{p}<0.0025$; females, $\mathrm{p}<0.0005$ ). This could be due to a change in the rate of relative growth after the puberty moult or to an abrupt increase in the size of the body part analysed, or to both simultaneously, in accordance with the patterns proposed by Somerton (1980). After maturity moult, both sexes show a change in allometry, although more marked in females. Thus, the allometry constant for males changes from 1.32 to 1.22 after moulting, while for females it changes from 1.51 to 1.37 (Fig. 7). Nevertheless, the change in the allometry constant is not statistically significant for males or females. There is a significant $(p<0.001)$ and relatively large increment in male $\mathrm{RChW}$ and in female AW. This means that there are 2 growth phases, each characterized by a single allometric equation. In both cases, the allometric lines have similar slopes but different elevations. Therefore, the onset of morphometric maturity is not apparent as a change in the relative growth rate of male RChW or female AW, but as a relatively large increment of these dimensions in relation to $\mathrm{CW}$ at the puberty moult.

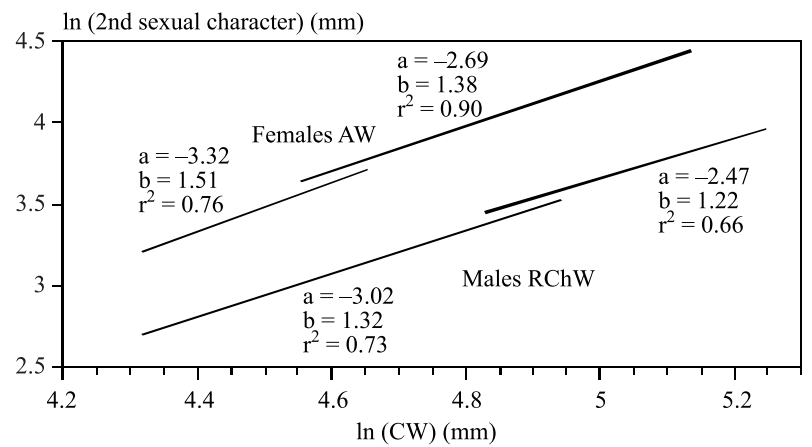

Fig. 7. Chaceon affinis. Allometric relationship between secondary sexual characters (male RChW and female AW) and carapace width (CW)

Other studies on Geryonidae have found no evidence of the above for males. For instance, Gaertner \& Laloé (1986) concluded that in male Chaceon maritae off Senegal the transition from immature to mature stage is not accompanied by a change in the allometry of secondary sexual characters. However, these authors found that female AW can be used to discriminate functionally mature individuals from immature individuals, using the allometric relationship between $\log (\mathrm{CL})$ and $\log (\mathrm{AW})$.

\section{Sexual maturity and other maturity-related conditions}

The reliability of the morphometric results for males was assessed using the GI. Cluster analyses using the most useful variables (carapace and cheliped dimensions) and the GI revealed 2 assemblages that were exactly the same as when only morphometric variables were used, indicating that gonad condition and morphometric maturity are related. In the MII group, 60\% $(57.69 \%)$ of the individuals did not present developed testes (GI between 0 and 0.1), the maximum GI observed being 0.66 , while in the MMI group almost $100 \%$ of the individuals had well-developed testes, the minimum GI observed for this group being 0.15 . More than $50 \%$ MMI had a GI $>0.5$. On the other hand, no individuals $<100 \mathrm{~mm}$ CW had well-developed testes (Fig. 8).

There is great variability in the GI values within each cluster. In the MII group some individuals may have reached sexual maturity despite not being morphometrically prepared for successful mating. On the other hand, large morphometrically mature individuals with low GI values were found, although this could be related to the reproductive cycle of the species.

There is a progressive decrease in the proportion of immature females as body size increases, while the proportion of individuals at advanced or mature stages 


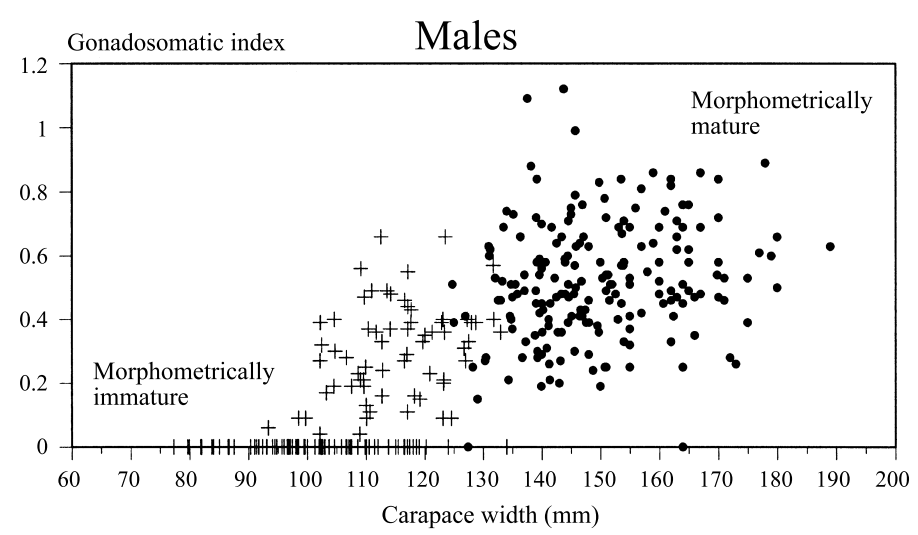

Fig. 8. Chaceon affinis. Evolution of gonadosomatic index of males by size and cluster composition

also increases. Individuals with immature ovaries $>120 \mathrm{~mm}$ CW were found, but there were also specimens as small as $\sim 96 \mathrm{~mm} \mathrm{CW}$ with ovaries at the most advanced stages of development (Fig. 9). Despite this, no females $<120 \mathrm{~mm}$ CW were caught in ovigerous condition or with egg remnants.

Although assemblages 2 and 3 were considered as a single group (MMI) within the morphometric analysis, and there are no significant differences in their allometric relationships, the intermediate or transition group was considered independently, because it represents a transition phase between immature and very mature individuals. Comparing initial results with the ovarian development stage, we observed that a high proportion of MII were also sexually immature (Fig. 10) and only a few (6\%) MII contained ovaries in other development stages. Therefore, some individuals reach sexual maturity prior to morphometric maturity. However, there was also a proportion of $\sim 24 \%$ of individuals classified as MMI that were not sexually mature and they all corresponded to the transition group. All the MMI individuals from Cluster 3 were also mature. Thus it seems that most females reach morphometric maturity before ovarian maturation.

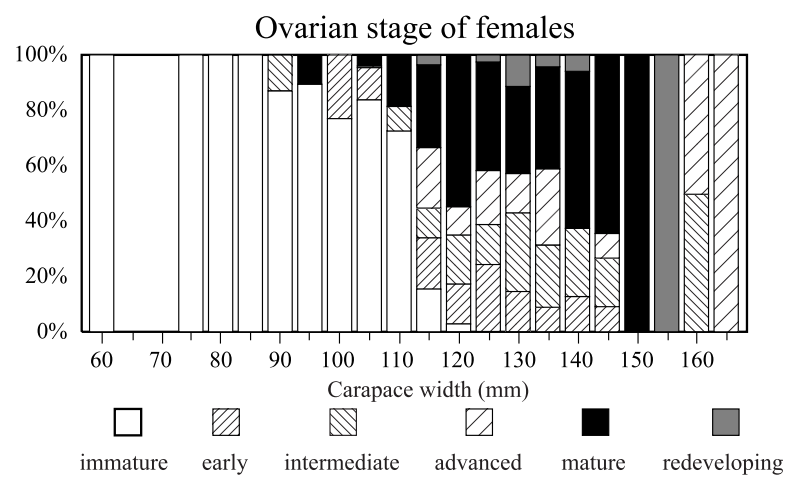

Fig. 9. Chaceon affinis. Proportion of females in each ovarian stage as a function of size

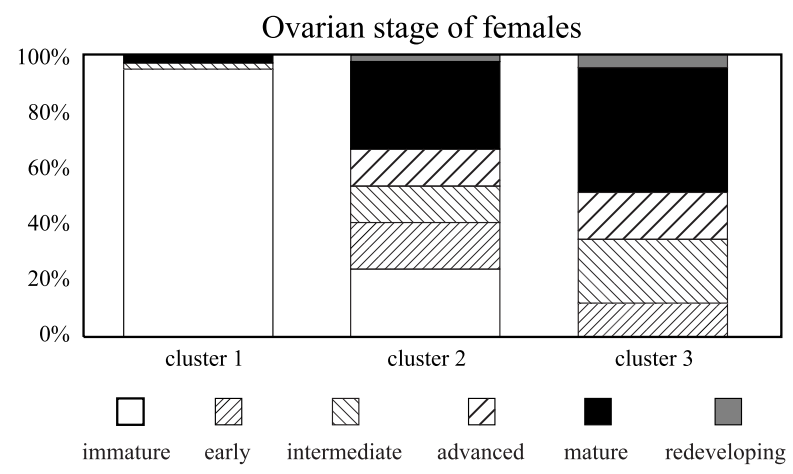

Fig. 10. Chaceon affinis. Proportion of females in each ovarian stage by cluster

Females < $95 \mathrm{~mm}$ CW present an abdomen narrower than the sternum, and most females $>120 \mathrm{~mm} \mathrm{CW}$ have a wide abdomen (Fig. 11). Only in the $85 \mathrm{~mm}$ CW size class was there 1 female with a typical adult abdomen. Few MII females had intermediate or mature abdomens, but all females from Cluster 3 had a mature abdomen. Most females from the transition group presented a typical mature abdomen, although some of them had abdomens in the other 2 stages. In this group there is a general increase in the proportion of individuals with mature abdomens as size increases. As for the ovarian stage, some females classified as MII had abdomens functional for reproduction, and only a few MMI did not have a functional abdomen to cover the eggs.

Analysing the proportion of each vulvae stage in relation to size, no females $<100 \mathrm{~mm} \mathrm{CW}$ had ever copulated, while most females $>120 \mathrm{~mm}$ CW presented evidence of copulation (open vulvae) (Fig. 12). Thus, none of the MII females had ever copulated, almost all females from Cluster 3 had successfully mated at some time, and most females from the transition group had open vulvae, meaning that they had also copulated. Analysing the proportion by size of each vulvae stage for the transition group, a decrease in the proportion of females that have never copulated is evident with increasing size.

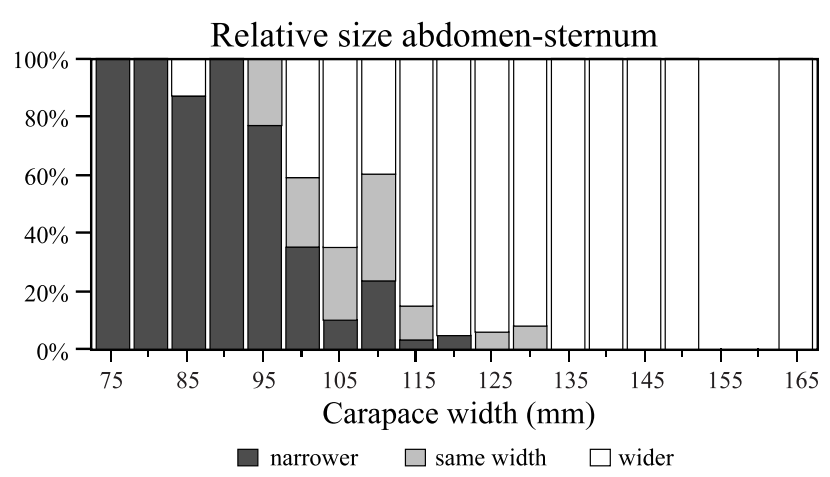

Fig. 11. Chaceon affinis. Proportion of females in each abdomen stage as a function of size 


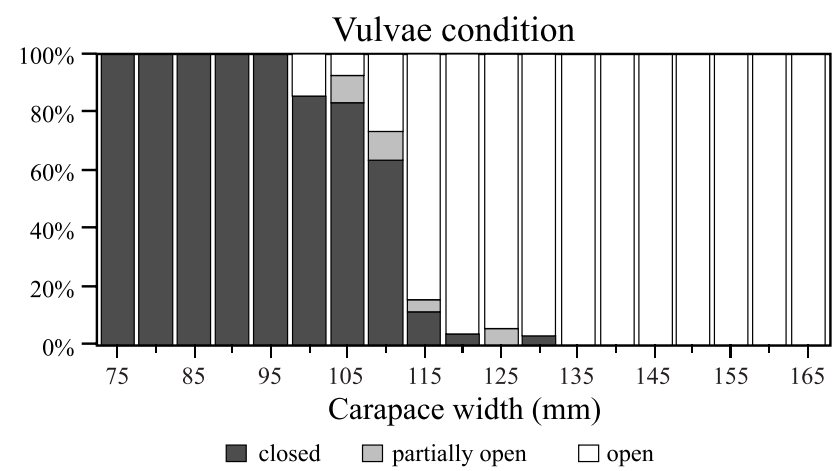

Fig. 12. Chaceon affinis. Proportion of females in each vulvae condition as a function of size

Chi-square analysis of contingency tables reject the hypothesis of independence $(\mathrm{p}<0.0001)$ of abdomen and vulvae morphology with regard to ovarian stage. Most individuals with abdomens narrower or as wide as the sternum had undeveloped ovaries in an immature stage, while most of those with wider abdomens contained ovaries in other developing stages. On the other hand, more than half the females with immature ovaries had a narrower abdomen, but $22.8 \%$ had abdomens wider than their sternum. The greater proportion of females with developed ovaries had abdomens wider than the sternum. This suggests that functional maturity of the hatching abdomen is attained prior to sexual maturity.

\section{Size at maturity and chronological sequence of maturation}

Size at maturity for male Chaceon affinis in the Canary Islands can be estimated from morphometric data. Fitting the proportion of individuals classified as 'adults' for each size interval to a logistic curve, the calculated size at maturity was $129 \mathrm{~mm} \mathrm{CW}$ (Fig. 13). In other studies on the Geryonidae, Gaertner \& Laloé

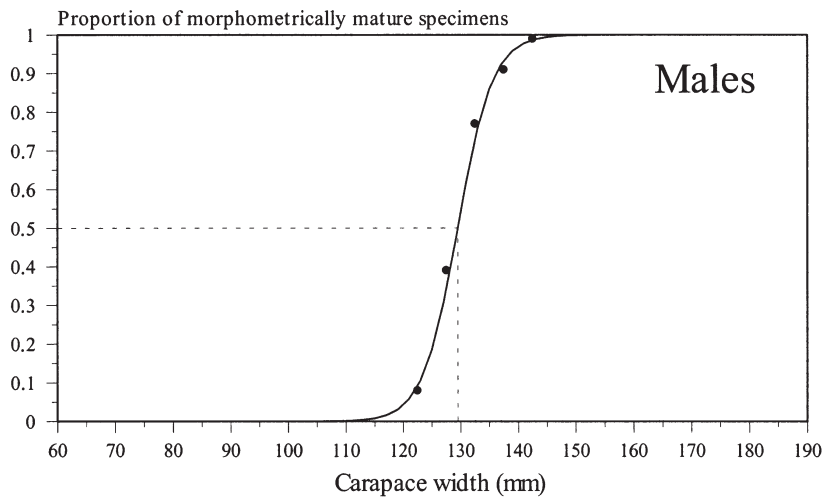

Fig. 13. Chaceon affinis. Logistic curve fitted to obtain size at maturity of males using morphometric characters
(1986) reported small (100 $\mathrm{mm} \mathrm{CW)} \mathrm{C.} \mathrm{maritae} \mathrm{males}$ from Senegal with developed gonads, Le Loeuff et al. (1978) estimated male size at maturity between 105 and $115 \mathrm{~mm}$ CW for C. maritae from the Ivory Coast using morphometric means, and Melville-Smith (1987) using histological analyses found that all male $C$. maritae $>80 \mathrm{~mm}$ CW in Namibia had spermatophores in the vas deferens and must therefore be considered sexually mature and capable of mating. The estimated size for C. affinis in the Canaries is slightly larger, but taking into account that individuals of this species reach greater sizes than the other Geryonidae species, the proposed approach should be considered reasonable.

Our analyses suggest that most females reach morphometric maturity before being sexually mature and functionally prepared for successful mating. Although functional capability for mating is related to morphologic changes, this is reached at a later stage of development than that represented by morphometric maturity, and is closely connected with behaviour pattern and ovarian stage. Applying the different criteria described, the proportion of females classified as mature were fit to each size class and the respective sizes at maturity obtained were (Fig. 14): morphometry, $99.26 \mathrm{~mm}$; abdomen stage, $108.00 \mathrm{~mm}$; ovarian stage, $108.58 \mathrm{~mm}$; vulvae stage, $113.41 \mathrm{~mm}$.

These results suggest the following sequence of maturation for females: (1) they reach morphometric maturity, (2) the abdomen attains optimum size relative to the sternum to be able to cover the eggs, at the same time that (3) they become sexually mature, and (4) finally copulate.

The nature of the data used to fit maturity curves, and in particular the discrimination procedure in the case of the morphometric analysis, produced 2 groups of logistic curves (Fig. 14) characterized by different shapes (slopes); i.e., the transition to morphometric maturity occurs over a very limited size range, whereas the transition to the other maturity characteristics is smoother and gradual. In this process, morphometric

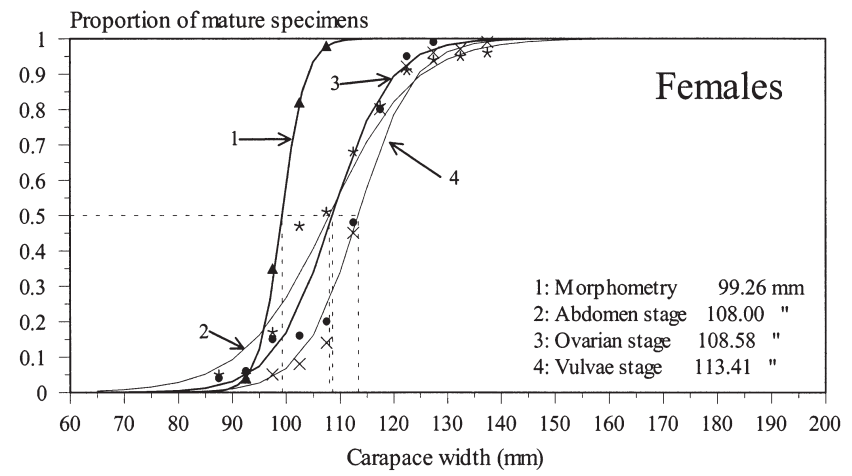

Fig. 14. Chaceon affinis. Logistic curve fitted to obtain size at maturity of females using different approaches 
maturity based on abdomen width should be considered the starting or breaking point from which other changes begin until successful mating occurs. Thus, an intermediate stage with a lag from the first step is observed whereby the abdomen is fully developed at the same time as the female is physiologically ready to reproduce. In summary, there is a delay between the first evidence of morphometric change to reproduction and the size at which females successfully copulate at the end of this process.

Therefore, size at maturity for female Chaceon affinis in the Canary Islands has to be considered to lie between 108 and $113 \mathrm{~mm} \mathrm{CW}$. Other authors working on different Geryonidae species have reported comparable data, if we take into account the lower mean size of these species in relation to $C$. affinis and the various criteria followed. Thus, Haefner (1977) estimated size at maturity for female $C$. quinquedens from the Atlantic North American coast at between 80 and $91 \mathrm{~mm} \mathrm{CW}$, based on the external aspect of the vulvae, gonad development, and morphometric criteria; Le Loeuff et al. (1978) determined that females of C. maritae from the Ivory Coast become sexually mature within the intermoult size range 80 to $90 \mathrm{~mm} \mathrm{CW}$, based on morphometric criteria; Melville-Smith (1987) estimated it at $100 \mathrm{~mm} \mathrm{CW}$ for the same species in Namibia; Gaertner \& Laloé (1986) estimated size at maturity of C. maritae in Senegal at $\sim 83 \mathrm{~mm} \mathrm{CW}$ based on morphometric means.

\section{Conclusion}

The current morphometric analyses provide evidence that allometric growth is maximum for male $\mathrm{ChW}$ and female AW. These dimorphisms can be related to reproductive behaviour patterns and identified as secondary sexual characters. Changes in allometry at the puberty moult are caused by an abrupt increment of these dimensions, although, unlike other Brachyura such as majid crabs, this step is less evident in Chaceon affinis and consequently more difficult to detect.

The use of size to determine size at maturity, whenever this event occurs, seems to be more appropriate, especially in the case of females, if sexual maturity and other maturity-related conditions such as vulvae morphology are taken into account, because of the smoothing or correcting effect they can have on the final result. Thus, size at maturity for male Chaceon affinis in the Canary Islands, estimated using morphometric data, was $129 \mathrm{~mm} \mathrm{CW}$; following the same criteria, females reach first maturity at $99.26 \mathrm{~mm} \mathrm{CW}$. However, the sequence of maturation obtained for females indicates an underestimation of size at maturity when only morphometric data are used, because of the delay between this event and the size at which they successfully mate. Therefore, the last value should be corrected towards a more conservative estimate ( 113 mm CW), and this could be taken as a general rule when morphometric data are used to estimate size at maturity.

Our results suggest that males attain first sexual maturation as opposed to a morphometric aptitude to mate, when they are able to compete and win against other males. On the other hand, females need to be morphometrically mature before completing physiological maturation.

Acknowledgements. We would like to express our gratitude to our colleagues from the Centro Oceanográfico de Canarias: José A. Díaz, Ma Teresa García, Ubaldo García-Talavera, José F. González, C. Perales and $\mathrm{M}^{\mathrm{a}}$ Eugenia Quintero, for their support in the sampling process carried out in this Centre, and of the Master and crew of MP 'Lahera' for their assistance.

\section{LITERATURE CITED}

Beyers BCJ, Wilke CG (1980) Quantitative stock survey and some biological and morphometric characteristics of the deep-sea red crab Geryon quinquedens off South West Africa. Fish Bull S Afr 13:9-19

Brown RB, Powell GC (1972) Size at maturity in the male Alaskan tanner crab, Chionoecetes bairdi, as determined by chela allometry, reproductive tract weights, and size of precopulatory males. J Fish Res Board Can 29:423-427

Cayre P, Bouchereau JL (1977) Biologie et résultats des pêches expérimentales du crabe Geryon quinquedens Smith, 1879 au large de la République Populaire du Congo. Doc Sci Centre Pointe-Noire (ORSTOM) NS) 51:1-30

Conan GY, Comeau M (1986) Functional maturity and terminal molt of male snow crab, Chionoecetes opilio. Can J Fish Aquat Sci 43:1710-1719

Davidson RJ, Marsden ID (1987) Size relationship and relative growth of the New Zealand swimming crab Ovalipes catharus (White,1843). J Crustac Biol 7:308-317

Dias CA, Seita Machado JF (1973) Preliminary report and relative abundance of deep-sea red crab (Geryon sp.) off Angola. Colln Scient Pap Int Commn SE Atl Fish 1:258-270

Elner RB, Koshio S, Hurley GV (1987) Mating behaviour of the deep-sea red crab, Geryon quinquedens Smith (Decapoda, Brachyura, Geryonidae). Crustaceana 52:194-201

Erdman RB, Blake NJ (1988) Reproductive ecology of female golden crabs, Geryon fenneri Manning and Holthuis, from southeastern Florida. J Crustac Biol 8:392-400

Gaertner D, Laloé F (1986) Étude biométrique de la taille à première maturité sexuelle de Geryon maritae Manning et Holthuis, 1981 du Sénégal. Oceanol Acta 9:479-487

Haefner PA (1977) Reproductive biology of the female deepsea red crab, Geryon quinquedens, from the Chesapeake Bight. Fish Bull US 75:91-102

Haefner PA (1990) Morphometry and size at maturity of Callinectes ornatus (Brachyura, Portunidae) in Bermuda. Bull Mar Sci 46:272-286

Haley SR (1973) On the use of morphometric data as a guide to reproductive maturity in the ghost crab, Ocypode ceratophthalmus (Pallas) (Brachyura, Ocypodidae). Pac Sci 27: 350-362 
Hartnoll RG (1974) Variation in growth pattern between some secondary characters in crabs (Decapoda Brachyura). Crustaceana 27:131-136

Intes A, Le Loeuff P (1976) Étude du crabe rouge profond Geryon quinquedens en Côte d'Ivoire. 1. Prospection le long du talus continental; résultats des pêches. Doc Sci Centre Rech Océanogr, Abidjan 7:101-112

Kjenerud J (1967) A find of Geryon affinis Milne-Edwuards y Bouvier, 1984 (Crustacea Decapoda) off the coast of Norway. Sarsia 29:193-198

Le Loeuff P, Cayre P, Intes A (1978) Étude du crabe rouge profond Geryon quinquedens en Côte d'Ivoire. ll. Éléments de biologie et d'ecologie avec référence aux résultats obtenus au Congo. Doc Sci Centre Rech Océanogr, Abidjan 9:17-65

López Abellán LJ, García-Talavera U (1992) Resultados de la campaña de prospección pesquera de los stocks de crustáceos profundos en aguas de la República de Angola 'Angola 9011'. Infmes Téc Inst Esp Oceanogr 119:1-73

López Abellán LJ, Santamaría MTG, Balguerías E (1994) Resultados de la campaña experimental de pesca, realizada en aguas del suroeste de la isla de Tenerife, Canarias 9206. Infmes Téc Inst Esp Oceanogr 147:1-62

Lozano IJ, Caldentey MA, Santana JL, González JA (1992) Crustáceos y peces capturados en una campaña de prospección en aguas profundas de Canarias. Actas V Simp Ibér Estud Bentos Mar 2:203-208

Lux FE, Ganz AR, Rathjen WF (1982) Marking studies on the red crab Geryon quinquedens Smith off southern New England. J Shellfish Res 2:71-80

Manning RB, Holthuis LB (1981) West African brachyuran crabs (Crustacea: Decapoda). Smithsonian Contr Zool 306:1-379

Manning RB, Holthuis LB (1984) Geryon fenneri, a new deepwater crab from Florida (Crustacea: Decapoda: Geryonidae). Proc Biol Soc Wash 97:666-673

Manning RB, Holthuis LB (1989) Two new genera and nine new species of geryonid crabs (Crustacea, Decapoda, Geryonidae). Proc Biol Soc Wash 102:50-77

Melville-Smith R (1987) The reproductive biology of Geryon

Editorial responsibility: Otto Kinne (Editor),

Oldendorf/Luhe, Germany maritae (Decapoda, Brachyura) off South West Africa/ Namibia. Crustaceana 53:259-275

Melville-Smith R (1988) The commercial fishery for and population dynamics of red crab Geryon maritae off South West Africa, 1976-1986. S Afr J Mar Sci 6:79-95

Milne Edwards A, Bouvier EL (1894) Crustacés décapodes provenant des campagnes du yacht l'Hirondelle (1886, 1887, 1888). Brachyures et anomoures. Résult Camp Sci Prince Albert 7:1-112

Mori M, Relini G (1982) Mating behaviour of Geryon longipes A. Milne Edwards 1881 (Crustacea: Decapoda: Brachyura) in captivity. Quad Lab Tecnol Pesca 3:173-178

Norusis MJ (1994) SPSS: statistical package for the social sciences 6.1 edn. SPSS Inc, Chicago

Sainte-Marie B, Hazel F (1992) Moulting and mating of snow crabs Chionoecetes opilio (O. Fabricius), in shallow waters of the northwestern Gulf of Saint Lawrence. Can J Fish Aquat Sci 49:1282-1293

Sainte-Marie B, Raymond S, Brethes JC (1995) Growth and maturation of the benthic stages of male snow crab, Chionoecetes opilio (Brachyura: Majidae). Can J Fish Aquat Sci 52:903-924

Samuelsen TJ (1975) The third record of Geryon affinis, A. Milne Edwards \& Bouvier (Crustacea, Decapoda) from western Norway. Sarsia 59:47-48

Sánchez F, Olaso I (1985) Presencia de Geryon affinis MilneEdwards y Bouvier, 1894, en el golfo de Vizcaya (Decapoda Brachyura). Boln Inst Esp Oceanogr 2:155-157

Santana JI, González JA, Lozano IJ, Caldentey MA, Lozano Soldevilla F, Gómez JA, Castillo R (1985) Informe preliminar sobre las pescas con nasas y palangres realizadas a bordo del buque 'Talirate' durante junio y julio de 1985. Dirección General de Pesca, Gobierno de Canarias, Las Palmas de Gran Canaria

Somerton DA (1980) A computer technique for estimating the size of sexual maturity in crabs. Can J Fish Aquat Sci $37: 1488-1494$

Zar JH (1974) Biostatistical analysis. Prentice-Hall, Inc, Englewood Cliffs, NJ

Submitted: October 18, 1999; Accepted: March 21, 2000

Proofs received from author(s): September 11, 2000 